Analitika: Jurnal Magister Psikologi UMA, Vol. 10 (2) Desember (2018)

ISSN: 2085-6601 (Print), ISSN: 2502-4590 (Online),

DOI: http://dx.doi.org/10.31289/analitika.v10i2.1791

\title{
ANALITIKA
}

Jurnal Magister Psikologi UMA

Available online http://ojs.uma.ac.id/index.php/ analitika

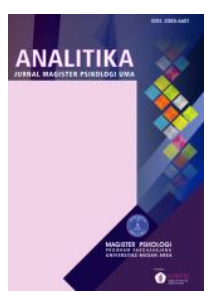

\section{Pengaruh Burnout dan Employee Engagement terhadap Intensi Turnover Karyawan Hotel}

\section{The Influence of Burnout and Employee Engagement toward Employee Turnover Intention of Hotel Employee}

\author{
Dinda Chairiza*, Zulkarnain \& Siti Zahreni \\ Prodi Psikologi Industri dan Organisasi, Fakultas Psikologi \\ Universitas Sumatera Utara, Indonesia
}

Diterima: Agustus 2018, disetujui: Desember 2018, dipublish: Desember 2018

*Corresponding author: E-mail: oath_keeperr@yahoo.com

\begin{abstract}
Abstrak
Turnover sebagai bentuk aktual dari intensi turnover merupakan fenomena umum yang terjadi didunia perhotelan. Ada berbagai faktor yang mempengaruhi intensi turnover karyawan antara lain burnout yang dialami karyawan dan employee engagement yang dimiliki karyawan. Penelitian ini bertujuan untuk mengetahui pengaruh burnout dan employee engagement terhadap intensi turnover karyawan di Hotel X Group. Hasil analisis berganda dari penelitian ini menunjukkan bahwa burnout dan employee engagement memiliki pengaruh terhadap intensi turnover karyawan di hotel X Group. Burnout berpengaruh positif dan employee engagement berpengaruh negatif terhadap intensi turnover karyawan di hotel X Group. Implikasi dari penelitian ini diharapkan perusahaan dapat mengetahui bahwa burnout dapat meningkatkan intensi turnover karyawan, sedangkan employee engagement dibutuhkan untuk menurunkan intensi turnover karyawan. Walaupun demikian, banyak hal lain di luar variabel di atas yang dapat mempengaruhi intensi turnover karyawan pada perusahaan perhotelan yang merupakan perusahaan keluarga pada khususnya.

Kata kunci: Burnout, Employee Engagement, Intensi Turnover, Karyawan Hotel.
\end{abstract}

\begin{abstract}
Turnover as an actual form of turnover intention is a general phenomena in hospitality business. There are various factors that influence employee turnover intention, such as burnout experienced by employees and employee engagement that employees. The aim of this research is to determine the influence of burnout and employee engagement toward employee turnover intention at X Group Hotel. Multiple analysis result of this research showed that burnout and employee engagement influenced towards employee turnover intention at X Group Hotel. Burnout positively influenced to employee turnover intention and employee engagement negatively influenced to employee turnover intention at $X$ Group Hotel. The implications of this research are expected the company can know that burnout can increase employee turnover intention, whereas employee engagement is needed to reduce employee turnover intention. However, many other things of the variables that can influence employee turnover intention on hospitality company, in particular if it is a family company.

Keywords: Burnout, Employee Engagement, Turnover Intention, The Hotel Employees.
\end{abstract}

How to Cite: Chairiza, D., Zulkarnain, Siti, Z. (2018), Pengaruh Burnout dan Employee Engagement terhadap Intensi Turnover Karyawan Hotel, Analitika: Jurnal Magister Psikologi UMA, 10 (2): 69 - 79. 


\section{PENDAHULUAN}

Dengan ketatnya persaingan bisnis di Indonesia, mempengaruhi berbagai bidang industri untuk dapat bertahan di pasar bisnis, termasuk bisnis perhotelan (Medan Bisnis, 2011). Di Medan, sampai tahun 2015 tercatat 55 hotel berbintang yang beroperasi (BPS, 2015). Hotel dalam perkembangannya, seharusnya mampu memberikan nilai lebih dalam memperlakukan para karyawan pada bisnis jasa perhotelan, karena merekalah ujung tombak kesuksesan bisnis ini (Medan Bisnis, 2014).

Di suatu perusahaan termasuk industri perhotelan, tentunya tidak lepas dari fenomena pengunduran diri karyawan dari tempat ia bekerja sekarang. AlBattat, Som \& Helalat (2013) mengungkapkan bahwa fenomena pengunduran diri karyawan merupakan permasalahan utama dalam industri perhotelan. Turnover dapat diartikan pada kondisi ketika karyawan memutuskan untuk keluar dari organisasi dengan sukarela (Jewell, 1998). Berdasarkan Novliadi (2008), intensi turnover banyak digunakan dalam penelitian yang bertujuan meneliti masalah turnover. Hasil penelitian tersebut mendukung penggunaan intensi turnover untuk memprediksi turnover, karena terdapat hubungan yang kuat antara keduanya.

Dari hasil pengambilan data mengenai beban kerja karyawan di Hotel X Group memang diketahui bahwa beban kerja karyawan lebih dari 100\% (Chairiza, 2015). Hal tersebut tentunya memberikan dampak tersendiri bagi karyawan yang melakukan pekerjaan dengan beban kerja yang tinggi tersebut.
Berdasarkan penelitian Haryono, Suryani \& Wulandari (2009), beban kerja yang berlebihan dapat menjadi salah satu penyebab kelelahan kerja. Kelelahan kerja inilah yang mengarah kepada burnout. Maslach, Schaufeli \& Leiter (2001) mengatakan bahwa beban kerja berhubungan langsung dengan aspek kelelahan (exhaustion) dari burnout.

Jika burnout diketahui dapat meningkatkan intensi turnover seseorang (Daryoto, 2012), maka ada faktor lain yang dapat menurunkan intensi turnover seseorang di dalam suatu perusahaan, yaitu employee engagement (Saks, 2006). Menurut survey yang dilakukan oleh Gallup (2013) kepada 1,4 juta karyawan, didapatkan hasil bahwa perusahaan yang memiliki karyawan yang engaged, 65\% lebih sedikit untuk melakukan turnover. Perusahaan tentu menginginkan peningkatan profit diperusahaan. Hal tersebut dapat ditempuh dengan meningkatkan employee engagement daripada hanya sekedar meningkatkan motivasi karyawan (Marciano, 2010). Fenomena yang tampak di hotel X Group adalah sebaliknya. Karyawan banyak mengeluhkan mengenai pekerjaan mereka, seperti pekerjaan yang tidak sesuai dengan gaji, pekerjaan yang terlalu banyak tekanan dan lain sebagainya. Beberapa karyawan hotel X Group juga mengatakan bahwa mereka sebenarnya ingin keluar dari perusahaan.

Dari fenomena yang muncul di hotel X Group tersebut, maka peneliti ingin meneliti lebih lanjut mengenai pengaruh dari burnout dan employee engagement terhadap intensi turnover karyawan pada hotel X Group 
Intensi turnover merupakan tanda awal terjadinya turnover, karena terdapat hubungan yang signifikan antara intensi turnover dengan turnover yang dilakukan karyawan (Mobley, Griffeth, Hand \& Meglino, 1979; Mobley, 2011). Intensi turnover dapat didefinisikan sebagai niat atau keinginan sengaja dan sadar untuk mencari alternatif pekerjaan lain di organisasi yang lain (Tett \& Meyer, 1993; Berry \& Morris, 2008; Wu, 2012; Rizwan, Sajid, Kamran, Mohsin, Ali \& Sajid, 2015).

Menurut Jacobs \& Roodt (2011) intensi turnover adalah niat seseorang untuk meninggalkan atau berhenti dari pekerjaan yang merupakan suatu jenis perilaku penarikan diri terhadap pekerjaan. Pada penelitian selanjutnya, Bothma \& Roodt (2012) mendefinisikan bahwa intensi turnover sebagai keinginan yang dilakukan secara sengaja untuk meninggalkan organisasi dan dianggap sebagai keputusan terakhir dalam urutan withdrawal cognition.

Dari beberapa pembahasan tersebut dapat ditarik kesimpulan bahwa intensi turnover adalah keinginan seseorang secara sadar dan sengaja untuk meninggalkan perusahaan tempat ia bekerja.

Maslach, Schaufeli \& Leiter (2001) menjelaskan bahwa berbagai penelitian Freudenberger dan Maslach memunculkan suatu istilah baru, yaitu burnout dimana ditandai dengan hilangnya motivasi dan komitmen seseorang. Maslach, Schaufeli \& Leiter (2001) mendefinisikan burnout sebagai respon jangka panjang stressor emosional dan interpersonal yang kronis dari pekerjaan yang terdiri dari tiga dimensi, yaitu kelelahan (exhaustion), sinis (cynism) dan perasaan tidak mampu (ineffficacy).

Demerouti, Bakker, Nachreiner \& Schaufeli (2001) dalam kajiannya mengenai burnout, menjelaskan burnout sebagai kondisi yang berkembang mengikuti dua proses. Proses pertama terkait dengan tuntutan pekerjaan (job demands) yang memicu kelelahan. Di sisi lain, kurangnya sumber daya pekerjaan (job resources) merepresentasikan proses kedua yang pada akhirnya menyebabkan perilaku menarik diri dan sikap negatif terhadap pekerjaan. Berdasarkan proses tersebut, maka burnout adalah konstruk yang lebih diwakili dua dimensi inti, yaitu exhaustion dan disengagement (from work).

Melanjuti penelitian sebelumnya, Demerouti et al. (2001); Demerouti \& Bakker (2007) mendefinisikan burnout sebagai sindrom psikologis yang muncul ketika karyawan berada pada lingkungan kerja dengan tuntutan pekerjaan yang tinggi ketika sumber daya yang dimiliki perusahaan tersebut rendah, kondisi ini menyebabkan karyawan menjadi kehabisan energi dan karyawan merasa tidak mampu, merasa tidak termotivasi dan kehilangan tanggung jawabnya dalam bekerja.

Dapat disimpulkan bahwa burnout merupakan suatu kondisi yang dialami pekerja yang ditandai menurunnya produktifitas kerja akibat kelelahan psikologis sebagai respon jangka panjang dari ketidaksesuaian antara lingkungan kerja dan kemampuan yang dimilikinya.

Kahn (1990) mendefinisikan employee engagement sebagai kesediaan 
karyawan untuk terlibat dalam aspek emosi, kognitif, dan fisik mereka dengan peran kerja mereka.

Menurut Schaufeli \& Bakker (2004), employee engagement sebagai suatu hal yang positif, saling memenuhi, dan melibatkannya dengan pikiran. Telaah lain yang dilakukan Saks (2006), employee engagement diartikan sebagai perilaku individu yang melibatkan aspek kognitif, emosional dan perilaku sehingga memunculkan kinerja yang unik yang berhubungan erat dengan komitmen organisasi, perilaku karyawan dalam organisasi serta keterlibatan karyawan dengan pekerjaannya.

Marciano (2010) mendefinisikan employee engagement sebagai suatu komitmen, dedikasi dan loyalitas seorang karyawan kepada perusahaan, atasan, pekerjaan dan rekan kerjanya. Sedangkan Wendel (2014) mengartikan employee engagement sebagai suatu keadaan emosional yang disebabkan oleh lingkungan kerja yang mendukung, sehingga mempengaruhi perilaku karyawan yang mengalaminya dan memberikan efek seperti peningkatan produktifitas kerja.

Dari berbagai definisi dari para ahli, dapat disimpulkan bahwa employee engagement adalah seberapa sering pekerja bersedia untuk menunjukkan kontribusi dan keterikatan secara mental dan fisik kepada pekerjaan serta perusahaannya sehingga tampak dari perilaku aktualnya dalam bekerja.

Industri perhotelan dikenal dengan pekerjaan yang padat, jam kerja yang panjang, beban kerja yang berat, shift kerja, libur kerja yang tidak teratur serta gaji yang relatif kecil. Dengan hal itu, intensi turnover di industri perhotelan patut diteliti (Lee, Huang \& Zhao, 2012).

Pada karyawan hotel dan restoran, jam kerja yang berupa shift serta pekerjaan yang berhubungan langsung dengan pelanggan, diasumsikan lebih sering mengalami burnout (Willemse, 2006). Penelitian Zhang \& Feng (2011) melaporkan bahwa dari aspek-aspek burnout yaitu exhaustion, cynism dan inefficacy, diketahui bahwa aspek kelelahan (exhaustion) menjadi prediktor langsung dari intensi turnover seseorang.

Ketika karyawan merasakan kelelahan (exhaustion), mereka cenderung lebih sensitif secara emosional dan cepat lelah secara fisik. Ketika karyawan sudah merasa seperti itu, mereka jadi tidak mampu dan tidak siap untuk melakukan pekerjaan mereka (Maslach, et al., 2001). Karyawan yang mengalami burnout lebih sering mengarah kepada perilaku negatif terhadap pekerjaannya, seperti berkeinginan untuk meninggalkan perusahaan tempat mereka bekerja saat ini (Babakus, Yavas \& Ashill, 2009; Hu, Schaufeli \& Taris, 2011).

Para manager pada industri perhotelan meyakini bahwa tingkat turnover yang tinggi merupakan fenomena yang merugikan dari sisi finansial perusahaan (Simons \& Hinkin, 2001). Intensi turnover seseorang dapat diturunkan dengan employee engagement (Saks, 2006).

Penelitian yang dilakukan oleh Schaufeli \& Bakker (2004) yang menyatakan bahwa employee engagement mempengaruhi intensi turnover seseorang. Lebih lanjut, kajian literatur Berry \& Morris (2008) 
menjelaskan bahwa employee engagement memiliki hubungan negatif dengan intensi turnover karyawan (Westhuizen, 2014).

Hasil serupa juga di temukan oleh Takawira, Coetzee \& Schreuder (2014), yang menyatakan bahwa aspek-aspek dari employee engagement seperti vigor, dedication dan absorption memiliki korelasi negatif dengan intensi turnover. Dengan korelasi yang paling signifikan dengan intensi turnover adalah aspek dedication dari employee engagement.

Penelitian Jones \& Harter (2005) mendapatkan hasil yang tak jauh berbeda. Dari penelitiannya dijelaskan bahwa ketika karyawan merasa engaged dengan pekerjaan dan perusahaannya mereka cenderung enggan meninggalkan perusahaan sebagai kebalikan dari intensi turnover. Karyawan akan merasa bahwa pekerjaan dan segala tantangan dari pekerjaan bukanlah suatu permasalahan yang membuatnya memiliki keinginan untuk melakukan turnover (Marciano, 2010).

Fenomena turnover merupakan suatu permasalahan klasik di perusahaan. Walaupun begitu, tingkat turnover yang tinggi tentunya memberikan dampak tersendiri bagi perusahaan yang mengalaminya. Ada berbagai macam dampak dari tingginya turnover disuatu perusahaan, antara lain yaitu dengan penurunan profit, meningkatnya dana pengeluaran perusahaan dikarenakan penambahan biaya dalam hal rekrutmen dan tidak efektifnya waktu yang dilakukan untuk merekrut karyawan baru (Simons \& Hinkin, 2001).
Turnover tidak terjadi begitu saja. Sebelum karyawan benar-benar melakukan turnover, mereka akan memiliki intensi turnover terlebih dahulu (Kaur et al., 2013). Pekerjaan di hotel dikenal dengan kegiatan pemberian pelayanan dan berhadapan langsung dengan pelanggan. Pekerjaan seperti ini dapat menyebabkan tekanan kerja. Telah diketahui bahwa tekanan kerja yang berkepanjangan dapat menyebabkan burnout pada karyawan (Civilidag, 2014).

Hasil-hasil penelitian mengenai burnout dan intensi turnover pun mendapatkan hasil yang sejalan dengan pernyataan Schaufeli \& Bakker (2004) yang menjelaskan bahwa burnout dapat mempengaruhi seseorang untuk memiliki intensi turnover. Semakin tinggi tingkat burnout yang dialami seseorang, maka semakin tinggi intensi turnovernya (Maslach et al., 2001; Leiter \& Maslach, 2009; Daryoto, 2012; Chen \& Yu, 2014).

Walaupun demikian, ada hal lain yang dapat mengurangi intensi turnover seseorang, yaitu employee engagement (Saks, 2006). Jika seseorang memiliki rasa keterikatan yang mendalam baik dari fisik, kognitif dan perasaan, maka karyawan tersebut akan mendedikasikan diri dan waktunya kepada perusahaan dimana ia bekerja (Marciano, 2010). Dengan demikian, seseorang tentu enggan dan keinginan untuk melakukan turnover akan kecil kemungkinan untuk muncul (Jones \& Harter, 2005).

Sebagaimana penelitian yang dilakukan oleh Schaufeli \& Bakker (2004) dan Jones \& Harter (2005) yang mendapatkan hasil bahwa employee engagement mempengaruhi intensi turnover seseorang. Dimana semakin 
tinggi employee engagement seseorang, maka intensi untuk melakukan turnover pada orang tersebut semakin rendah (Takawira, Coetzee \& Schreuder, 2014; Westhuizen, 2014).

Dari pemaparan tersebut, dibuatlah hipotesis dari penelitian ini, yaitu:

H1 : Ada pengaruh positif burnout terhadap intensi turnover karyawan di Hotel X Group.

H2 : Ada pengaruh negatif employee engagement terhadap intensi turnover karyawan di Hotel X Group.

H3 : Ada pengaruh burnout dan employee engagement terhadap intensi turnover karyawan di Hotel X Group.

\section{Bagan Kerangka Pemikiran Penelitian}

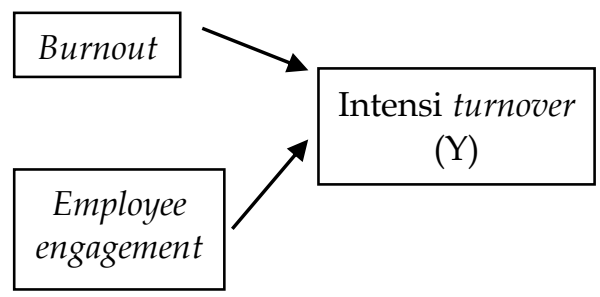

\section{METODE PENELITIAN}

Variabel terikat (Dependent variable) : Intensi turnover (Y), Variabel bebas (Independent variable) : Burnout (X1) dan Employee engagement (X2)

Penelitian ini merupakan penelitian populasi. Dimana keseluruhan anggota populasi merupakan sampel penelitian. Jumlah populasi dalam penelitian ini adalah 216 orang yang merupakan seluruh karyawan Hotel X Group.

Skala intensi turnover disusun dengan mengacu pada dimensi intensi turnover dari Mobley (2011), yaitu 1) Thinking of quitting, 2) Intention to search dan 3) Intention to quit. Total aitem skala ini berjumlah 14 aitem dengan koefisien korelasi berkisar dari 0.388 sampai dengan $0.568, \alpha=0.829$.

Semua aitem dibuat dalam bentuk skala Likert lima titik (1= sangat tidak sesuai, $5=$ sangat sesuai untuk aitem favorable; sebagian aitem kami konstruksi secara terbalik untuk aitem unfavorable).

Skala burnout disusun dengan mengacu pada dimensi burnout yang dikemukakan oleh Maslach, Schaufeli \& Leiter (2001), yaitu 1) Kelelahan (exhaustion), 2) Sinis (cynism) dan 3) Perasaan tidak mampu (inefficacy). Pada skala ini terdapat 11 aitem dengan koefisien korelasi berkisar dari 0.342 sampai dengan $0.762, \alpha=0.824$.

Semua item dibuat dalam bentuk skala Likert lima titik (1= sangat tidak sesuai, $5=$ sangat sesuai untuk aitem favorable; sebagian aitem kami konstruksi secara terbalik untuk aitem unfavorable).

Skala employee engagement menggunakan skala Utrecht Work Engagement Scale (UWES) yang terdiri dari 17 aitem yang dibuat oleh Schaufeli \& Bakker (2003). Skala ini mencakup 3 dimensi employee engagement, yaitu 1) Vigor, 2) Dedication dan 3) Absorption. Setelah diuji coba, total terdapat 14 aitem dengan koefisien korelasi berkisar dari 0.332 sampai dengan $0.654, \alpha=$ 0.853

Skala ini menyediakan 7 pilihan jawaban sesuai dengan skala aslinya. Semua aitem dalam skala ini merupakan aitem favorable dengan skor 0 sampai dengan 6. Semakin tinggi skor skala, maka semakin mendukung pernyataan employee engagement. 
Penelitian ini menggunakan teknik analisis multiple regression dengan bantuan program spss versi 17.00 for window.

\section{HASIL DAN PEMBAHASAN}

H1: Ada pengaruh positif burnout terhadap intensi turnover karyawan di Hotel X Group. Berdasarkan hasil analisa statistik didapatkan bahwa $\mathrm{R}$ square bernilai .038 dan nilai koefisien regresi variabel burnout +.211 . Didapatkan $\mathrm{p}<$ 0,05 maka H1 diterima.

H2: Ada pengaruh negatif employee engagement terhadap intensi turnover karyawan di Hotel X Group. Pada uji hipotesis ini didapatkan R square bernilai .059 dan nilai koefisien regresi variabel employee engagament -.178 . Nilai $\mathrm{p}<0,05$ maka $\mathrm{H} 2$ diterima.

H3: Ada pengaruh burnout dan employee engagement terhadap intensi turnover karyawan di Hotel X Group. Hasil penelitian menunjukkan bahwa burnout dan employee engagement berpengaruh terhadap intensi turnover karyawan $\left(\mathrm{R}=.271, \mathrm{R}^{2}=.073, \mathrm{~F}=8.440\right)$. Dikarenakan nilai $\mathrm{P}<0.05$, maka $\mathrm{H} 3$ diterima dan $\mathrm{H}_{0}$ ditolak.

Dari hasil penelitian yang peneliti lakukan diketahui bahwa burnout mempengaruhi secara positif intensi turnover sebesar 3,8\%. Hal ini berarti bahwa semakin seseorang merasakan burnout, maka intensi turnover karyawan semakin tinggi. Hal ini mendukung hasil penelitian Schaufeli \& Bakker (2004) yang menunjukkan hasil bahwa ada pengaruh burnout terhadap intensi turnover seseorang. Hasil penelitian ini juga mendapatkan hasil yang serupa dengan penelitian Leiter \& Maslach
(2009); Zhang \& Feng (2011); Daryoto (2012) serta Chen \& Yu (2014) yang menunjukkan bahwa ada hubungan positif antara burnout dengan intensi turnover.

Ada beberapa alasan yang dapat menjelaskan bahwa burnout dapat mempengaruhi intensi turnover seseorang. Pertama, jika karyawan merasakan burnout, maka gejala-gejala yang dirasakan karyawan antara lain seperti merasa pusing, lelah, tidak semangat dan merasa tidak mampu dalam bekerja serta absensi kerja meningkat (Cordes \& Dougherty, 1993). Saat karyawan merasakan gejala tersebut, mereka cenderung lebih sensitif secara emosional dan cepat lelah secara fisik. Ketika karyawan sudah merasa seperti itu, mereka jadi tidak mampu dan tidak siap untuk melakukan pekerjaan mereka (Maslach, et al., 2001). Dengan gejala negatif yang muncul pada karyawan yang mengalami burnout, tentunya akan mempengaruhi produktifitas karyawan dalam bekerja (Maslach, et al., 2001). Karyawan menjadi tidak puas dengan pekerjaannya sehingga memunculkan keinginan untuk melakukan turnover (Maslach, et al., 2001; AlBattat, Som \& Helalat, 2013).

Alasan kedua, penelitian yang dilakukan oleh Kim \& Stoner (2008) mendapatkan hasil bahwa burnout mempengaruhi intensi turnover karyawan karena saat karyawan mengalami burnout, karyawan rentan mengalami stres sehingga mempengaruhi kelekatannya dengan perusahaan. Karyawan menjadi enggan untuk tetap tinggal diperusahaan dan 
membuat karyawan memiliki keinginan untuk meninggalkan perusahaannya.

Ketiga, ketika karyawan mengalami burnout, mereka akan gagal untuk mengenal secara pasti peranan yang dimainkan olehnya. Malahan, mereka cenderung menyalahkan apapun yang ada di sekeliling mereka, termasuk organisasi tempat mereka bekerja dan mereka juga bersikap sinis terhadap pertolongan orang lain. Dengan demikian, jika organisasi gagal untuk mewujudkan suasana kerja yang sehat dan kurang mampu untuk meyakinkan bahwa karyawan merupakan bahagian besar daripada organisasi, maka karyawan akan merasa kecewa dan seterusnya tidak akan memberikan sambutan terhadap penawaran maupun peluang-peluang untuk mengembangkan diri ke tingkat yang lebih tinggi, yang pada akhirnya membuat karyawan memiliki keinginan untuk melakukan turnover (Zulkarnain, 2011).

Dari hasil penelitian juga menjawab hipotesa kedua yaitu ada pengaruh negatif employee engagement terhadap intensi turnover di Hotel X. Hasil studi ini sejalan dengan penelitian Schaufeli \& Bakker (2004); Berry \& Morris (2008) serta Westhuizen (2014) yang memang menunjukkan hasil bahwa ada pengaruh negatif employee engagement terhadap intensi turnover seseorang.

Ada beberapa alasan yang dapat menjelaskan hubungan negatif tersebut. Alasan pertama, jika karyawan sudah merasa engaged dengan pekerjaan dan perusahaannya, karyawan akan menunjukkan sikap seperti membawa ide baru kedalam pekerjaannya, merasa antusias akan pekerjaannya, mengambil inisiatif dalam melakukan pekerjaannya, secara aktif akan mencari cara untuk meningkatkan kemampuan dirinya, orang lain maupun untuk perusahaannya, secara konsisten akan mencapai tujuan pekerjaannya, memiliki rasa ingin tahu yang tinggi, memberikan dukungan kepada kelompok kerjanya, fokus pada tugasnya dan berkomitmen kepada organisasi (Marciano, 2010). Dengan begitu, bagi karyawan yang engaged, berbagai bentuk tekanan pekerjaan dari perusahaan tentu tidak mempengaruhi karyawan untuk memiliki keinginan melakukan turnover. Karyawan akan merasa bahwa pekerjaan dan segala tantangan dari pekerjaan bukanlah suatu permasalahan yang membuatnya memiliki keinginan untuk melakukan turnover (Marciano, 2010).

Alasan kedua, jika karyawan sudah merasa engaged, karyawan terikat secara emosional dan rasional. Jika karyawan sudah terikat secara emosional, mereka akan merasa puas dengan pekerjaannya, pekerjaannya memunculkan inspirasi baginya serta karyawan akan merasa mendapat penguatan dari pekerjaannya dan merasa menjadi bagian dari perusahaannya. Hal inilah yang menyebabkan karyawan yang merasa engaged akan enggan meninggalkan perusahaan (Towers Perrin, 2003).

Alasan ketiga, karyawan yang engaged akan memunculkan dimensidimensi yang tampak pada perilaku karyawannya, yaitu vigor berhubungan dengan naik turunnya level energi dan ketahanan mental karyawan saat bekerja, keinginan untuk memberikan usaha lebih pada pekerjaannya dan menunjukkan ketekunan ketika 
menghadapi kesulitan pada pekerjaanya. Dedication pada karyawan yang engaged membuat karyawan merasa antusias, memiliki insipirasi, serta merasa bangga dengan pekerjaannya. Absorption pada karyawan yang engaged membuat karyawan merasa senang akan pekerjaannya dan menjalani pekerjaannya tanpa peduli dengan waktu. Jika karyawan sudah merasa demikian, jelaslah bahwa semakin karyawan merasa engaged, maka intensi turnover karyawan semakin rendah (Lee \& Shin, 2005).

Jika karyawan sudah memiliki rasa keterikatan yang mendalam baik dari fisik, kognitif dan perasaan, maka karyawan tersebut akan mendedikasikan diri dan waktunya kepada perusahaan dimana ia bekerja (Marciano, 2010). Dengan demikian, seseorang tentu enggan dan keinginan untuk melakukan turnover akan kecil kemungkinan untuk muncul, karena karyawan lebih memilih untuk tetap tinggal di perusahaan dan memberikan performa terbaiknya kepada perusahaan sehingga memberikan dampak positif pada perusahaan tempat ia bekerja (Jones \& Harter, 2005).

\section{SIMPULAN}

Berdasarkan hasil analisa dan interpretasi data penelitian dapat ditarik kesimpulan mengenai hasil penelitian, bahwa Burnout berpengaruh positif terhadap intensi turnover karyawan di Hotel X Group. Artinya semakin tinggi burnout yang dialami karyawan, maka semakin tinggi intensi turnover karyawan. Demikian sebaliknya. Terdapat pengaruh negatif employee engagement terhadap intensi turnover karyawan di Hotel X Group. Artinya semakin tinggi employee engagement, maka semakin rendah intensi turnover karyawan. Begitu juga sebaliknya. 3) Terdapat pengaruh burnout dan employee engagement terhadap intensi turnover karyawan di Hotel X Group.

\section{DAFTAR PUSTAKA}

AlBattat, A.R., Som, A.P. M \& Helalat, A.S. (2013). Overcoming staff turnover in the hospitality industry using Mobley's model. International Journal of Learning and Development, 3 (6), 64-71.

Babakus, E., Yavas, U. \& Ashill, N.J. (2009). The role of customer orientation as a moderator of the job demand - burnout performance relationship : A surface level trait perspective. Journal of Retailing, 85 (4), 480-492.

Berry, M.L. \& Morris, M.L. (2008). The impact of employee engagement factors and job satisfaction on turnover intent. (Paper), The University of Tennesse, Knoxville.

Bothma, F.C. \& Roodt, G. (2012). Work - based identity and work engagement as potential antecedents of task performance and turnover intention: Unravelling a complex relationship. SA Journal of Industrial Psychology, 38 (1), 1-17.

Badan Pusat Statistik. (2015). Sumatera utara dalam angka 2015. (Laporan Tahunan), Sumatera Utara

Chairiza, D. (2015). Work design melalui analisa beban kerja guna mengurangi turnover karyawan hotel $X$. (Laporan PKPP Organisasi - Tidak di Publikasi). Universitas Sumatera Utara, Medan.

Chen, C.F. \& Yu, T. (2014). Effects of positive vs negative forces on the burnout commitment - turnover relationship. Journal of Service Management, 25 (3), 388-410.

Civilidag, A. (2014) Hotel employees' mobbing, burnout, job satisfaction and perceived organizational support: A research on hospitality in Turkey. European Scientific Journal, 10 (35), 1-22.

Cordes, C.L \& Dougherty, T.W. (1993). A review and an integration of research on job burnout. Academy of Management Review, $18(4), 621-656$. 
Daryoto, D.W. (2012). Penerapan intervensi flexible working arrangement (fwa) dan community of practice (cop) untuk menurunkan tingkat pengunduran diri karyawan di kantor akuntan public (kap) $a b c \quad \mathcal{E}$ rekan. (Tesis). Universitas Indonesia, Depok.

Demerouti, E. \& Bakker, A.B. (2007). The oldenburg burnout inventory: $A$ good alternative to measure burnout (and engagement). Diunduh pada tanggal 23 Desember 2015 dari http://scholar.google.co.id/scholar_url?ur l=http://www.beanmanaged.com/doc/pdf /arnoldbakker/articles/articles_arnold_ba kker_173.pdf\&hl=en\&sa=X\&scisig=AAGBf m3qMbR5D57buUy5G312Mz7SoCFtrw\&no ssl=1\&oi=scholarr\&ved=oahUKEwjIo8672q HMAhUJtpQKHWqDB9AQgAMIGigBMA A

Demerouti, E., Bakker, A.B., Nachreiner, F. \& Schaufeli, W.B. (2001). The jobs demands - resources model of burnout. Journal of Applied Psychology, 86 (3), 499-512.

Gallup. (2013). State of the American workplace: Employee engagement insights for U.S. business leaders. Diunduh pada tanggal 7 Januari $2016 \quad$ dari https://www.google.co.id/url/sa=t\&source =web\&rct=j\&url=http://employeeengage ment.com/wpcontent/uploads/2013/o6/Gallup-2013State-of-the-American-WorkplaceReport.pdf\&ved=oahUKEwiıZZKiraHMAh VFFp QKHUFCAyQQFggyMAI\&usg=AFQjCNEJ 7_JylwlklrMnJvUSrT-

6G9ysHw\&sig2=hMydZCkA3WoinhTjQDt vow

Hariyono, W., Suryani, D. \& Wulandari, Y. (2009). Hubungan antara beban kerja, stres kerja dan tingkat konflik dengan kelelahan kerja perawat di rumah sakit Islam Yogyakarta PHDI kota Yogyakarta. Jurnal KES MAS UAD, 3 (3), 162-232.

Jacobs, E.J. \& Roodt, G. (2011). The mediating effect of knowledge sharing between organisational culture and turnover intentions of professional nurses. $S A$ of Information Management, 13 (1), 1-6.

Jewell, L.N. (1998) Contemporary industrial: Organizational psychology, (3 ${ }^{\text {th }}$ Edition). California: Brooks/Cole Publishing Company, Pacific Grove.

Jones, J.R. \& Harter, J.K. (2015). Race effects on the employee engagement - turnover intention relationship. Journal of Leadership and Organizational Studies, 11 (2), 78-88.

Kahn, W.A. (1990). Psychological conditions of personal engagement and disengagement at work. Academy of Management Journal, 33(4), 692-724.

Kaur, B., Mohindru \& Pankaj. (2013). Antecedents of turnover intentions: A literature review. Global Journal of Management and Bussiness Studies, 3 (10), 1219-1230.

Kim, H. \& Stoner, M. (2008). Burnout and turnover intention among social workers: effects of role stress, job autonomy and social support. Administration in Social Work. 32(3), 5-25

Lee, C.C., Huang, S.H. \& Zhao, C.Y. (2012). A study on factors affecting turnover intention of hotel employees. Asian Economic and Financial Review, 2 (7), 866875 .

Lee, K.E. \& Shin, K.H. (2005). Job burnout, engagement and turnover intention of dietitians and chefs at a contract foodservice management company. J Community Nutrition 7(2), 100-106.

Leiter, M.P. \& Maslach, C. (2009). Nurse turnover: The mediating role of burnout. Journal of Nursing Management, 17, 331339.

Marciano, P.L. (2010). Carrots and sticks don't work: Build a culture of employee engagement with the principles of respect. New York : Mc Graw Hill.

Maslach, C., Schaufeli, W.B. \& Leiter, M.P. (2001). Job burnout. Annual Reviews Psychology, 53, 397-422.

Medan Bisnis. (15 Juni 2011). Bisnis hotel di Medan semakin ketat. Diunduh dari http://www.medanbisnisdaily.com/news/ arsip/read/2011/o6/15/38811/bisnis-hoteldi-medan-semakin-ketat/\#.VxToLrcmGx4

Medan Bisnis. (5 Januari 2014). Bisnis perhotelan dan kuliner tetap "seksi". Diunduh dari http://www.medanbisnisdaily.com/news/ $\mathrm{read} / 2014 / 01 / 05 / 71283 / 2014$-bisnisperhotelan-dan-kuliner-tetapseksi/\#.VxToLrcmGx5

Mobley, W.H. (2011). Pergantian karyawan: Sebab akibat dan pengendaliannya. Seri Manajemen No.127. Terjemahan. Penerbit: PPM.

Mobley, W.H., Griffeth, R.W., Hand, H.H.\& Meglino, B.M. (1979). Review and conceptual analysis of the employee 
turnover process. Psychological Bulletin, 86 (3), 493-522.

Novliadi, F. (2008). Intensi Turnover Karyawan ditinjau dari Budaya Perusahaan dan Kepuasan Kerja, Unpublished undergraduate thesis, Universitas Sumatera Utara, Medan.

Rizwan, M., Sayid, H.U.S., Kamran, M., Mohsin, M., Ali, N. \& Sajid, H.M. (2015). Determinants of turnover intentions in government and private employees: An empirical study from Pakistan. IOSR Journal of Bussiness and Management (IOSR-JBM), 44-51.

Saks, A.M. (2006). Antecedents and consequences of employee engagement. Journal of Managerial Psychology, 2 (7), 6oo-619.

Schaufeli, W.B. \& Bakker, A.B. (2004). Job demands, job resources, and their relationship with burnout and engagement: A multiple - sample study. Journal of Organizational Behavior, 25,293-315.

Simons, T. \& Hinkin, T. (2001). The effect of employee turnover on hotel profits: A test across multiple hotels. Cornell Hotel and Restaurant Administration Quarterly, 42 (4), 65-69.

Takawira, N., Coetzee, M. \& Schreuder, D. (2014). Job embeddeness, work engagement and turnover intention of staff in higher education institution: An exploratory study. SA Journal of Human Resource Management, 12 (1), 1-10.

Tett, R.P \& Meyer, J.P. (1993). Job satisfaction, organizational commitment, turnover intention, and turnover: Path analysis based on meta - analytic findings. Personnel Psychology, 46, 259-293.

Wendel, S. (2014). An employee's guide to employee engagement. Principal scientist at hello wallet. Diunduh pada tanggal 2 Desember 2015 dari www.hellowallet.com/research/employers -guide-employee-engagement/

Westhuizen, N.V.D. (2014). Turnover intention and employee engagement: exploring eliciting factors in South African audit firms. (Thesis). Stellenbosch University, Western Cape.

Willemse, S.A. (2006). Burnout. coping and engagement in the hospitality industry. (Mini-Dissertation). North-West University, Potchefstroom Campus, Potchefstroom.

$\mathrm{Wu}$, X. (2012). Factors influencing employee turnover intension: The case of retail industri in Bangkok, Thailand. (Dissertation), University of the Thai Chamber of Commerce, Bangkok.

Zhang, Y. \& Feng, X. (2011). The relationship between job satisfaction, burnout, and turnover intention among physicians from urban state owned medical institution in Hubei, China: A Cross - Sectional Study. BMC Health Services Research, 11, 235-247.

Zulkarnain. (2011). Dampak burnout terhadap kualitas kehidupan bekerja pada pekerja public service. Disajikan pada Prosiding Seminar Ilmiah Dies Natalis USU ke-59 (SI-Dies 2011), Medan, Indonesia. 